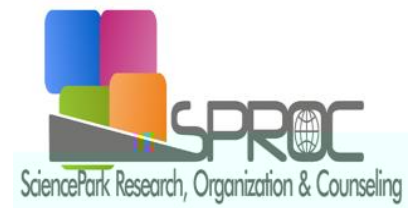

$\mathrm{P}$

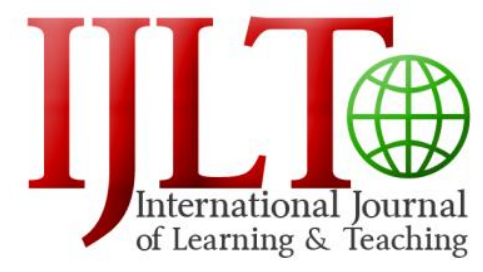

www.ij-It.eu

\title{
Findings from the assessment of students' learning outcomes in engineering mathematics
}

Chung Lim Christopher Kwan*, $P$

\author{
I
}

I

Suggested Citation

I

International Journal of Learning and Teaching 9

$S$

I

$P$

L

Abstract

$\mathrm{P}$

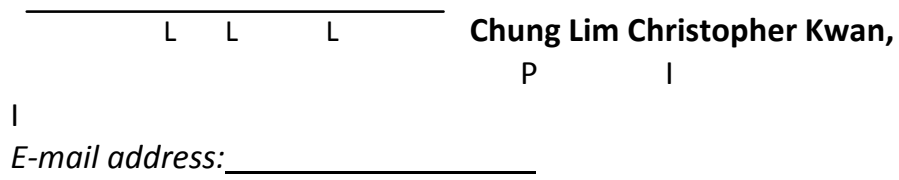




\section{Introduction}

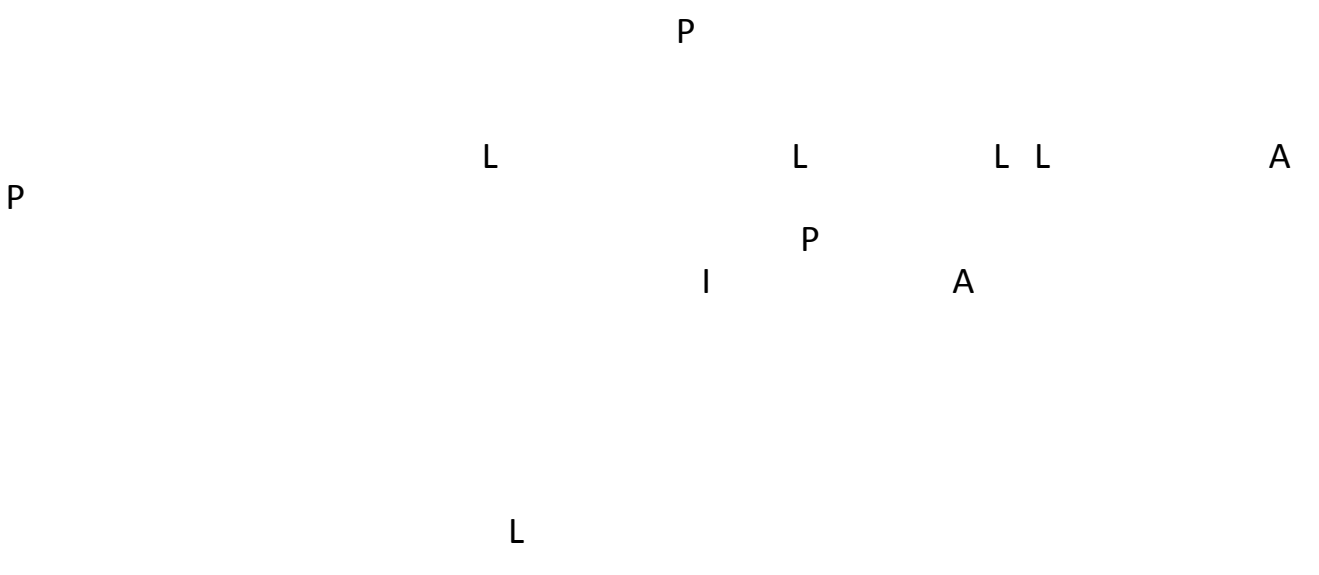

A

A

2. Context of the study 
Learning and Teaching 9

3. Method

$\mathrm{P}$ 
3.1. Questions

\section{P}

A

$P$

P

$P$

P

${ }^{v} v$

V

P

4. Results

$\mathrm{P}$

P

P A

P

L

P 

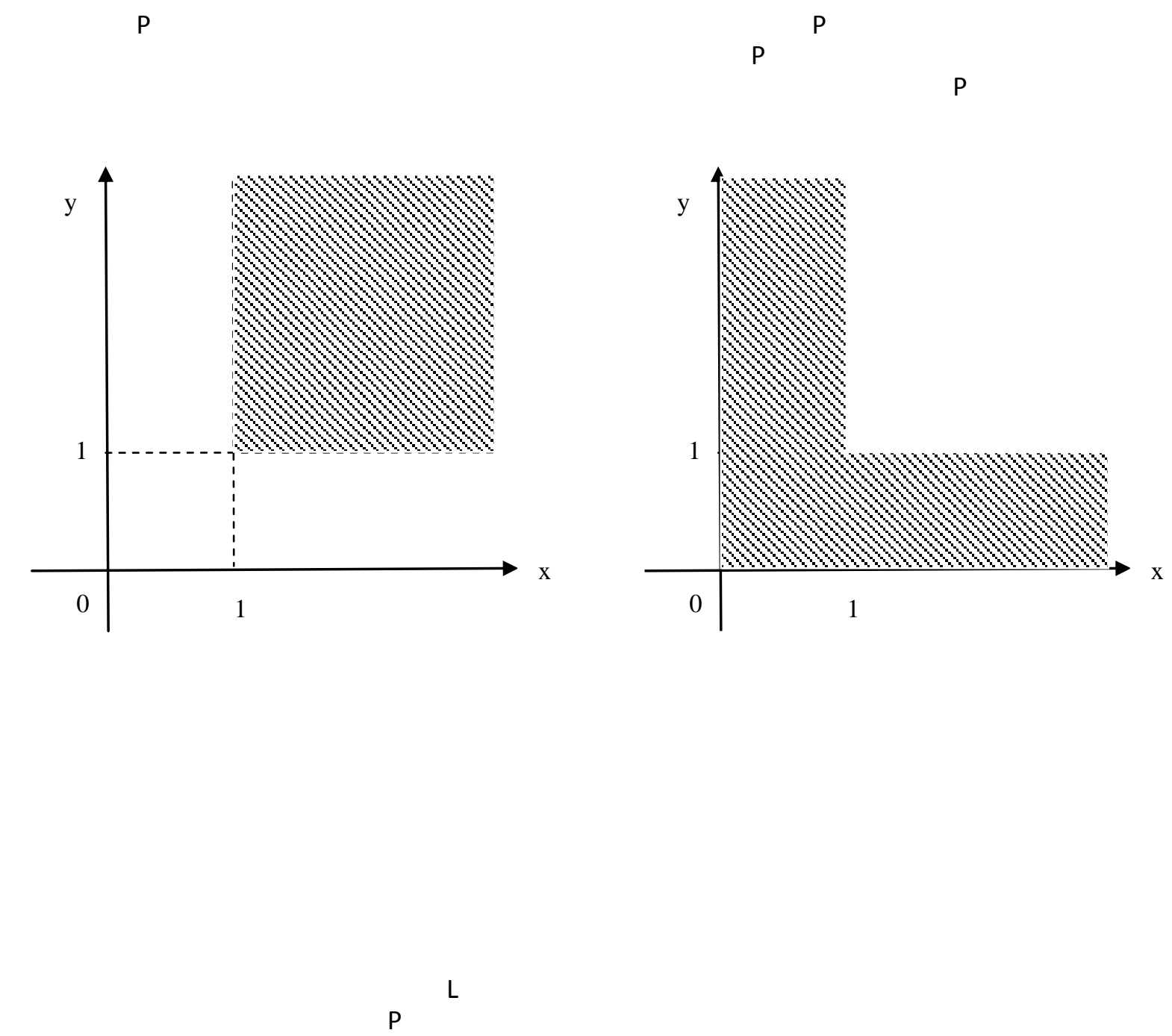
I

Learning and Teaching 9

$\mathrm{L}$

5. Discussion and Conclusion

$\mathrm{P}$

$\mathrm{P}$

$\mathrm{P}$

International Journal of

P

A

P

$\mathrm{L}$

L

296 


\section{References}

A

A A A I

Teaching for quality learning at university, 2nd Edition

$\mathrm{L}$

Evaluating the quality of learning: The SOLO taxonomy.

P

।

A

A

A

$P$

A

24th Annual Conference of the Australasian Association for Engineering Education,

Engineering Science and Education Journal 10

P

International Journal of Engineering Education

14

P

P 